\title{
Occurrence of acrylamide and other heat-induced compounds in panela: Relationship with physicochemical and antioxidant parameters
}

\author{
Faver Gómez-Narváeza, Marta Mesías ${ }^{b}$, Cristina Delgado-Andradeb, José Contreras- \\ Calderóna , Fabiola Ubillúsc, Gastón Cruzc, Francisco J. Moralesb \\ ${ }^{\text {a }}$ Bioali Research Group, Food Department, Faculty of Pharmaceutical and Food Sciences, University of \\ Antioquia, Calle 67 No. 53 - 108, Ciudad Universitaria, Medellín, \\ Colombia \\ b Instituto de Ciencia y Tecnología de Alimentos y Nutrición (ICTAN-CSIC), C/ José Antonio Novais, I0, \\ Madrid E-28040, Spain \\ ' Universidad de Piura, Av. Ramón Mugica I3I, Piura, Peru \\ Institute of Food Science, Technology and Nutrition, ICTAN-CSIC, Madrid 28040, Spain
}

\begin{abstract}
Panela is a natural, unrefined non-centrifugal sugar obtained by intense dehydration of sugarcane juice. Acrylamide, hydroxymethylfurfural (HMF), and furfural were determined in 40 panela samples distributed as granulated and block according to the technological process. Colour, browning, moisture, water activity, $\mathrm{pH}$ and antioxidant capacity were also evaluated. Acrylamide ranged between 60 and $3058 \mu \mathrm{g} / \mathrm{kg}$; granulated panela reporting the highest concentration $(812 \mu \mathrm{g} / \mathrm{kg})$ compared with block panela $(540 \mu \mathrm{g} / \mathrm{kg})$. The lower content in HMF and furfural, the intense dehydration, and the extensive darkening of granulated panela suggested the browning reactions were boosted due to the application of more severe thermal treatments. Principal component analysis showed a significant relationship between the panela presentation and the concentration of the analysed compounds. Benchmark values considering both types of processes would help to establish mitigation initiatives in panela products. The chromatic parameter a* could be used as an indirect index of the acrylamide content in panela.
\end{abstract}

KEYWORDS: Panela, Acrylamide, Furan compounds, Antioxidants, Non-enzymatic browning

\section{INTRODUCTION}

Panela is the natural sugar obtained by intense dehydration of the sugarcane juice without centrifugation. Panela is also known as unrefined non-centrifugal sugar or non-centrifugal cane sugar. Most of the production of panela is artisanal, which is part of the local economy in many Latinamerican, Caribbean, Asian and African countries. The process allows the retention and concentration in the panela of valuable constituents of the sugarcane juice including minerals, vitamins, phenolic compounds, amino acids, and proteins (Jaffé, 2012). At least 26 different bioactive phytochemicals have been identified in panela (Takara, Matsui, Wada, Ichiba, \& Nakasone, 2002). The presence of bioactive health-promoting compounds increase the beneficial effects on human health, so that anticarcinogenic, antitoxic, cytoprotective, anti-inflammatory or antiatherogic actions have been described (Jaffé, 20I2). Despite all the positive biological effects, limited information is available regarding the physicochemical profile and some other technological attributes of this traditional food product whose consumption is growing in USA and Europe (Jaffé, 20I2). In fact, the international commercial interest of the panela sector is leading this industry to accommodate with the standards of quality and safety prevailing in the destination countries.

According to the sugarcane composition, rich in sugars $(\approx 14 \mathrm{~g} / 100 \mathrm{~g})$ and nitrogen compounds $(\approx 0.40 \mathrm{~g} / 100$ g) (Durán-Castro, 2010), the Maillard reaction and sugar caramelisation are the major reactions taking place 
during the production of panela. Caramelisation requires temperatures $>120^{\circ} \mathrm{C}$ and $\mathrm{pH}$ between 3 and 9 , whereas the Maillard reaction proceeds at temperatures $>50^{\circ} \mathrm{C}$ and is favoured at $\mathrm{pH} 4-7$ (Kroh, 1994). Considering the high level of free asparagine $(\approx 0.07 \mathrm{~g} / 100 \mathrm{~g})$ (Durán-Castro, 2010), the presence of reducing sugars, the thermal treatment applied, and the low moisture reached in the final product, panela is prone to the formation of acrylamide (Vargas Lasso, Talero Pérez, Trujillo Suárez, \& Caballero, 20I4). Acrylamide has been identified as a public health concern due to its relation with different types of cancer (EFSA, 20I5). The recent Commission Regulation (EU) 2017/2158 establishes mitigation measures and benchmark levels for the reduction of the presence of acrylamide in different groups of foods. French fries, potato chips, cereal derived products and coffee has been as group of foods under tight surveillance (European Commission, 2017). Panela is not included in the first release of the acrylamide forthcoming years to introduce other foods as well as to reconsider the benchmark levels already established.

On the other hand, furan compounds such as hydroxymethylfurfural (HMF) and furfural could be generated in panela through both caramelization and Maillard reactions. In technological terms, HMF may be interesting since it is one of the best-known indicators of the extent of the non-enzymatic browning reactions and has demonstrated its suitability to monitor the heat damage in other food matrices (Rufián-Henares \& DelgadoAndrade, 2009). From a toxicological point of view, HMF exhibits a potential genotoxic and mutagenic activity following metabolic activation to 5-sulphoxymethylfurfural (SMF) (Sachse et al., 2016). Some studies indicate that HMF and SMF may act as an initiator of colon cancer in rats inducing hepatocellular adenomas in murine model (Svendsen, Husøy, Glatt, Paulsen, \& Alexander, 2009), whereas furfural may lead to hepatotoxicity (EFSA, 2005).

The main purpose of this work was to identify the range of occurrence of acrylamide in panela commercialised as granulated and block in South American and European countries. This knowledge is necessary to define reference values for any further strategy to reduce the formation of acrylamide in this commodity, but also in what extent should be applied. HMF and furfural were also evaluated to complete the thermal damage profile. In addition, physicochemical characteristics and antioxidant activity were assessed.

\section{MATERIALS AND METHODS}

\section{I. Chemicals and reagents}

Potassium hexacyanoferrate (II) trihydrate (98\%, Carrez-I) and zinc acetate dehydrate (> 99\%, Carrez-II) were obtained from Sigma (St. Louis, USA). 13C3-labelled acrylamide (99\% isotopic purity) was obtained from Cambridge Isotope Laboratories (Andover, MA, USA). Formic acid (98\%) and methanol (99.5\%) were from Panreac (Barcelona, Spain). Deionized water was obtained from a Milli-Q Integral 5 water purification system (Millipore, Billerica, MA, USA). All other chemicals, solvents and reagents were of analytical grade.

\subsection{Samples}

Forty samples of commercial non-centrifugal cane sugar (panela) acquired in May-June 2018 were analysed. Sixteen samples of panela in block were obtained from different trapiches (name given to traditional panela factories) settled at the municipalities of Yolombo, Yalí, Amalfi and Vegachí of the department of Antioquia provided by Doble A Agroindustrias SAS (Colombia). The remaining samples were granulated panela purchased in supermarkets of European countries or provided by producers of Cooperativa Norandino (Piura, Peru). Samples were stored according to the producer recommendation at room temperature until analysis. 


\subsection{LC-ESI-MS-MS determination of acrylamide}

Sample extraction was based on the method described by Mesías and Morales (2015) with some modifications. Panela samples $(0.5 \mathrm{~g})$ were weighed and mixed with $9.4 \mathrm{~mL}$ of water in polypropylene centrifugal tubes. Mixture was spiked with $100 \mu \mathrm{L}$ of a $5 \mu \mathrm{g} / \mathrm{mL}\left[{ }^{13} \mathrm{C}_{3}\right]$-acrylamide methanolic solution as internal standard and later homogenized (Ultra Turrax, IKA, Mod-TIO basic, Germany) for 10 min. Afterwards, sample was treated with $250 \mu \mathrm{L}$ of each Carrez I ( $15 \mathrm{~g}$ potassium ferrocyanide/ $100 \mathrm{~mL}$ water) and Carrez II (30 g zinc acetate/100 mL water) solutions and centrifuged (9000 g for $10 \mathrm{~min}$ ) at $4{ }^{\circ} \mathrm{C}$. Samples were cleaned up by using of Oasis-HLB cartridges and extracts were analysed as described in Mesías and Morales (2015). The recovery of acrylamide was between 90 and 106\%. The relative standard deviations (RSD) for the precision, repeatability and reproducibility of the analyses were calculated as $2.8 \%$, $1.2 \%$ and $2.5 \%$, respectively. The limit of the quantitation was set at $20 \mu \mathrm{g} / \mathrm{kg}$. Results of acrylamide were expressed as $\mu \mathrm{g} / \mathrm{kg}$ of sample. Samples were analysed by duplicate.

\subsection{Determination of $\mathrm{HMF}$ and furfural}

HMF and furfural were determined by HPLC-DAD as described by Mesías, Holgado, Márquez-Ruíz, and Morales (2015). The limit of quantification was set at $0.6 \mathrm{mg} / \mathrm{kg}$ and $0.3 \mathrm{mg} / \mathrm{kg}$ for HMF and furfural, respectively. Results were expressed as $\mathrm{mg} / \mathrm{kg}$ sample. Samples were analysed by duplicate.

\subsection{Determination of browning}

Fractions of supernatants $(200 \mu \mathrm{L})$ obtained in the preparation of sample for HMF and furfural determination were placed in a 96-wells plate. Browning at $420 \mathrm{~nm}$ was rapidly measured at room temperature using a BioTekSynergyTM HT-multimode microplate spectrophotometer (BioTek Instruments, Winooski, VT, USA). Samples were analysed by duplicate and results expressed as absorbance units/g of sample.

\subsection{Colour determination}

Colour measurements were made at room temperature using a HunterLab Spectrophotometer CM-3500D colorimeter (Hunter Associates laboratory, Stamford, Connecticut, USA). Three independent measurements of $a^{*}$ (redness), $b^{*}$ (yellowness) and $L^{*}$ (lightness) parameters were carried out. For block panela, colour was measured on the outside of the solid in order to compare the results with the information described in the literature. In addition, colour was also measured after grating the block of panela. $E$ index was calculated according to the following equation: $E=\left(L^{2}+a^{2}+b^{2}\right)^{1 / 2}$. The equipment was calibrated with a standard calibration white plate CR-A43 (L/93.80; a/0.3I56; b/0.3319).

\subsection{Sample extraction for the measurement of the total phenolic content and the antioxidant activity}

The extraction was performed following the procedure described by Pérez-jiménez and Saura-Calixto (2005). Briefly, $0.1 \mathrm{~g}$ of samples was placed in a tube and $6 \mathrm{~mL}$ of acidic methanol/water $(50: 50 \mathrm{v} / \mathrm{v}, \mathrm{pH} 2)$ were added. The tube was thoroughly shaken at room temperature for $20 \mathrm{~min}$ and centrifuged at $2500 \mathrm{~g}$ for $10 \mathrm{~min}$, and the supernatant was recovered. Four millilitres of the same acidic methanol/water were added to the residue, and the shaking and centrifugation steps were repeated. The second methanolic extract was combined with the first one. When necessary, proper dilutions with distilled water were made for antioxidant activity and total phenolic content measurements. Extraction was performed by duplicate.

\subsection{Antioxidant activity assay (ABTS)}

The ABTS assay was conducted as described by Rufián-Henares and Delgado-Andrade (2009) with slight modifications. The $A B T S+\%$ was produced by reacting $7 \mathrm{mM}$ ABTS stock solution with $2.45 \mathrm{mM}$ potassium 
persulphate and allowing the mixture to stand in the dark at room temperature for $12-16 \mathrm{~h}$ before use. The $\mathrm{ABTS}^{+}$working solution (stable for 2 days) was diluted with a mixture of ethanol:water (50:50) to an absorbance of $0.70 \pm 0.02$ at $730 \mathrm{~nm}$. For the analyses, $40 \mu \mathrm{L}$ of sample, blank or Trolox standard and 200 $\mu \mathrm{L}$ of $5 \mathrm{mM} \mathrm{pH} 8.4$ phosphate buffer were added with $60 \mu \mathrm{L}$ of diluted ABTS+\% solution. The absorbance reading was taken at 10 min using the microplate reader previously described. Aqueous solutions of Trolox were used for calibration (15-125 $\mu \mathrm{M}$ ). Results were expressed as $\mu$ mol equivalents of Trolox (TEAC)/g of sample. All measurements were performed in triplicate.

\subsection{Total phenolic content (TPC)}

Total phenolic content was determined according to the Folin-Ciocalteu method based on Marfil et al. (201I) with slight modifications. Briefly, $80 \mu \mathrm{L}$ of sample, blank or gallic acid standard, $1520 \mu \mathrm{L}$ of distilled water and $300 \mu \mathrm{L}$ of $20 \% \mathrm{Na}_{2} \mathrm{CO}_{3}(\mathrm{w} / \mathrm{v})$ were mixed with $100 \mu \mathrm{L}$ of commercial Folin-Ciocalteu's reagent and incubated for $\mathrm{I} h$ at room temperature. Absorbance was measured at $750 \mathrm{~nm}$ by using a Biotek Synergy HT multi-mode microplate reader (BioTek ${ }^{\circledR}$ Instruments Inc., USA). Quantification was carried out based on the standard curve of gallic acid $(25-300 \mathrm{mg} / \mathrm{L})$, and results were expressed as $\mathrm{mg}$ gallic acid equivalent $(\mathrm{GAE}) / \mathrm{g}$ of sample. All measurements were performed in triplicate.

\subsection{Complementary analyses}

Moisture was determined gravimetrically to constant weight in an oven at $105{ }^{\circ} \mathrm{C}$ for $24 \mathrm{~h}$ according to the AOAC (1999) method. The water activity was measured at $25^{\circ} \mathrm{C}$ by an AquaLAB CX-2 (Decagon Devices Inc., Pullman, WA). Samples were analysed by duplicate. For the $\mathrm{pH}$ measurement, sample (I g) was mixed with $100 \mathrm{~mL}$ of water and vortexed for $3 \mathrm{~min}$. The mixture was held at room temperature for $\mathrm{I} \mathrm{h}$ and centrifuged to separate impurities. $\mathrm{pH}$ of the supernatant was measured using a CG-837 pH meter (Schott, Mainz, Germany). Samples were analysed by duplicate.

\section{I I. Statistical analysis}

Statistical analyses were performed by using SPSS version 16.0 (SPSS Inc., Chicago, IL) and Statgraphics Centurion XV (Herndon, VA, USA). The statistical significance of the variables was tested applying analysis of variance (ANOVA one-way) and the test of mean comparison according to Fisher least significant difference (LSD). Homogeneity of variances was determined with the Levene's test. Relationships between the different variables were evaluated by computing Pearson's linear correlation coefficient. All statistical parameters were evaluated at $\mathrm{P}<0.05$ significance level. Multivariate statistics (including principal component analyses (PCA) and cluster analyses (CA)) were employed to quantitatively investigate relationships among the samples of panela respect to the indicators analysed. Variables were standardised before the analysis and principal components with eigenvalues greater than one were selected. CA was made through k-means methods using square Euclidean distances.

\section{RESULTS AND DISCUSSION}

Panela is commercially available either as granulated or block panela. Each format is characteristic of the technological process applied, and more precisely, they differ on the extent of dehydration reached. Briefly, both products share the same initial steps in the process that includes sugarcane crushing and juice extraction, cleaning, clarification and $\mathrm{pH}$ regulation. In the block panela, the cane juice is concentrated until $90-92^{\circ}$ Brix, followed by cooling, beating and moulding in block. In the case of granulated panela, the cane juice is concentrated until $96^{\circ} \mathrm{Brix}$, then beating to crystallised and sifted (Durán-Castro, 2010). In addition, the manufacture of granulated panela is mostly artisanal and leads to a final product with lower moisture content. For European consumers, granulated panela has several advantages of convenience such as easier 
dosage, higher solubility, and stability during storage (Mujica, Guerra, \& Soto, 2008). The set of samples were segmented according to granulated $(n=24)$ and block $(n=16)$ panela.

\section{I. Moisture, Aw and pH}

Table I shows the results of moisture, $\mathrm{Aw}$ and $\mathrm{pH}$ of the samples analysed. The moisture ranged from 0.6 to $10.0 \%$. Block panela reported significantly higher moisture content than the granulated panela, 8.7 and $3.1 \%$, respectively. The wide variability in the moisture content between the two type of products, even within the same group, probably is due to the different manufacturing process conditions, that is mainly artisanal and poorly controlled (Jaffé, 2015). Some producers of granulated panela promote the dehydration and granulation steps by circulation of air during beating (Guerra \& Mujica, 2010). Our results for moisture are in line with previous studies for granulated panela (2.1-4.4\%) (Asikin et al., 2016; Guerra \& Mujica, 2010). In the same line, Durán-Castro (2010) already described that moisture content of block panela was higher than granulated panela, $6.0-9.0 \%$ and $4.0-5.0 \%$, respectively. Other authors observed a moisture content of $3.9 \%$ (Lee et al., 2018) and between 1.5 and $15.8 \%$ (Jaffé, 2015) for unspecified panela samples.

The Aw was between 0.37 and 0.74 showing the same trend as moisture, with significantly higher values for block panela samples. This range is wider than that reported by Asikin et al. (20I4) (Aw=0.35-0.4I) and similar to those described by the same authors years later (Asikin et al., 2016) ( $A w=0.55-0.64)$, and by Guerra and Mujica $(2010)$ in granulated samples $(A w=0.5 I-0.69)$. Due to its higher $A w$, block panela may have a shorter shelf life by effect of microbial and oxidative spoilage.

The $\mathrm{pH}$ in panela ranged from 5.3 to 7.I. Granulated and block panela samples showed similar average values, 6.I and 5.9, respectively, which is in agreement with the literature (Guerra \& Mujica, 2010; Lee et al., 2018). The $\mathrm{pH}$ parameter is a critical variable during manufacturing of panela regardless granulated or block. The $\mathrm{pH}$ of fresh cane juice must be increased from 5.0-5.2 to at least 5.8 to clarify efficiently the juice (Durán-Castro, 2010), thus eliminating the impurities and insoluble solids in suspension (called cachaza). The addition of a suspension of lime (calcium oxide) or sodium bicarbonate allows the production of panela with lighter colour and avoids the hydrolysis of sucrose. $\mathrm{A} \mathrm{pH}$ between 6.0 and 6.5 is required to ensure a product free of cachaza which is a quality criteria for identification of defective panela (Durán-Castro, 2010).

\subsection{Acrylamide}

Acrylamide was detected in all the panela samples regardless the type of processing. The acrylamide content ranged from 60 to $3058 \mu \mathrm{g} / \mathrm{kg}$. However, average acrylamide content was higher in granulated panela (8/2 $\mu \mathrm{g} / \mathrm{kg}$ ) as compared with block panela $(540 \mu \mathrm{g} / \mathrm{kg}$ ) (Table 2). Acrylamide is formed at temperatures higher than $120^{\circ} \mathrm{C}$ from reducing sugars and asparagine (Capuano \& Fogliano, 201I). Agronomical factors and varieties of sugarcane have a significant influence on the final composition of the raw material, leading to variability in the level of these potential precursors of acrylamide (Durán-Castro, 2010). In this line, Mujica et al. (2008) observed different composition of reducing sugars in two commercial varieties of sugarcane, Puerto Rico 6I,632 and Mayarí 55I4. Another critical factor is maturity stage at harvest. Mature sugarcane contents the highest sucrose level and is lower in glucose. Rapid processing of the sugarcane must be performed to avoid sucrose inversion and panela reprocessing. Immature sugarcane harvesting or longer storage times will impair the crystallisation process. This fact leads to prolonged heat treatment, then to greater heat damage (Durán-Castro, 2010) and, in turn, higher presence of acrylamide. On the other hand, the water evaporation during the beating step applied to obtain the granulated panela is a concentration process also justifies the increase of the acrylamide content in this product form. It should be also highlighted that all block panela came from Colombia, with lower variability between samples than 
granulated forms. Colombian trapiches have a more standardized manufacturing process than Peruvian, although still very artisanal. Among producer countries, Colombia has more expertise in panela production, plant and equipment availability. Colombian government has even published an official document on the scientific concept of acrylamide on panela (INS, 20I2). Though improved equipment has been developed (La Madrid, Mendoza Orbegoso, Saavedra, \& Marcelo, 2017), Peruvian trapiches perform a traditional process, with lower degree of technification, producing granulated panela and, therefore, higher variability in the characteristics of the final product is expected.

There are scarce data in the literature regarding acrylamide content in panela. Hoenicke and Gatermann (2005) found values around $140 \mu \mathrm{g} / \mathrm{kg}$ in raw sugar, which are close to the lower levels described in the present study. Vargas Lasso et al. (2014) measured acrylamide content by HPLC-UV/VIS in different stages of panela processing, obtaining concentrations that range between not detected in cane juice to $2000 \mu \mathrm{g} / \mathrm{kg}$ in the final product. Not detected values were observed in clarified and white washed samples whereas levels increased during the stages of concentration and evaporation $(389 \mu \mathrm{g} / \mathrm{kg})$, beating $(596 \mu \mathrm{g} / \mathrm{kg})$ and shaking, moulding and cooling $(997 \mu \mathrm{g} / \mathrm{kg})$ until reaching the final product $(1600-2000 \mu \mathrm{g} / \mathrm{kg})$. These results corroborate that temperature and moisture content are very important physical parameters, which affect the formation of acrylamide in the process of panela production, determining its accelerated formation at high temperatures. Recently, the Colombian National Institute of Drug and Foods Vigilance collected from different Colombian producers (Invima, 2018).

\subsection{HMF and furfural}

The content of sugars and amino acids in non-centrifugal cane sugar (Asikin et al., 2017), the low Aw and high temperatures applied during process justify the formation of furfurals in panela. HMF has two main pathways of formation: i) as an intermediate during Maillard reaction, and ii) a product of caramelisation by dehydration of sugar (Silva, Silva, Perestrelo, Nunes, \& Câmara, 2018). Both routes are favoured at slight acid $\mathrm{pH}$. However, the formation of HMF in the analysed panela samples was quite low compared with other food matrices such as coffee $(100-1900 \mathrm{mg} / \mathrm{kg})$, dried fruit $(25-2900 \mathrm{mg} / \mathrm{kg})$ or vinegar balsamic $(316.4-$ $3525 \mathrm{I} .3 \mathrm{mg} / \mathrm{kg}$ ) (Capuano \& Fogliano, 20I I). HMF ranged from lower than 0.6 (LOQ) to $14.8 \mathrm{mg} / \mathrm{kg}$ (Table 2). Granulated panela showed significantly lower average levels $(3.2 \mathrm{mg} / \mathrm{kg})$ than block samples $(5.9 \mathrm{mg} / \mathrm{kg})$. To the best of our knowledge, there are no studies of HMF content in panela.

Furfural in panela was not expected in large amounts since major sugarcane juice are hexoses (glucose and fructose) together with sucrose (Asikin et al., 2017) and not pentoses (Eskin et al., 20I3). However, furfural was detected in granulated and block panela, ranging between lower than 0.3 (LOQ) $-4.5 \mathrm{mg} / \mathrm{kg}$. It may be hypothesized that furfural was formed from the interconversion of HMF because of strong heating conditions (Wen et al., 2016). Furfural exhibited the same behaviour as HMF, being the average content significantly lower in granulated samples $(1.5 \mathrm{mg} / \mathrm{kg}$ ) as compared to block panela $(3.0 \mathrm{mg} / \mathrm{kg})$. No significant correlations were found between acrylamide with HMF and furfural contents in panela.

\subsection{Browning and colour parameters}

During the progress of the non-enzymatic browning reactions (caramelization and the Maillard reaction), there is an increase in the formation of coloured compounds. Among the myriad of compounds formed, they can be roughly divided in low molecular weight and high molecular weight compounds, as melanoidins. One of the quality attributes appreciated by the panela consumers is the solubility, therefore coloured compounds are expected to be low and intermediate molecular weight compounds, which are water soluble (Mesías \& Delgado-Andrade, 2017). The browning measured as absorbance at $420 \mathrm{~nm}$ of the soluble fraction 
of panela is a parameter to monitor the extent of the browning reactions. In this study, browning ranged from 1.5 to 1 I.5 units/g of sample (Table 2). The higher browning was found in granulated panela samples (5.2 units/g) with significant differences compared with the group of block panela ( 2.2 units/g). As previously mentioned, the process of obtaining granulated panela requires reaching a higher concentration of solids $\left(96^{\circ} \mathrm{Brix}\right)$ and, therefore, a longer thermal process at high temperatures than that of the block panela (90$92^{\circ} \mathrm{Brix}$ ) (Durán-Castro, 2010). This fact, in turn, means the rapid progress of the advanced stage of the non-enzymatic browning reaction, and consequently, the disappearance of intermediate compounds (HMF and furfural) but an increase of final products in granulated panela. Sugar degradation is characterised by an initial enolisation followed by dehydration or $\beta$-elimination, dicarboxylic cleaving, retro-aldol reaction and aldol condensation. Furfurals are considered products of the reaction, but if the reaction proceeds, furfurals take part in the formation of colour polymers (Cämmerer, Wedzicha, \& Kroh, 1999). In addition to the consumption of furfurals in the formation of colour compounds, the necessary beating of the concentrated sugarcane syrup to produce the granulated panela probably favours the volatilization of furfural compounds.

Browning was not correlated with the HMF content but a negative correlation was found with furfural $(r=-0.3895, p=0.0150)$. These data are similar to those reported by Asikin et al. (2014), where the presence of 3-deoxy-glucosone (3-DG) as a precursor of HMF was not directly correlated with brown colour development in non-centrifugal cane sugar. As mentioned before, strong heating conditions could lead to the interconversion of HMF into furfural, that in the development of the reaction is degraded to form advanced non-enzymatic browning compounds such as melanoidins, which could explain the negative correlation between furfural and absorbance at $420 \mathrm{~nm}$. Browning was also significantly correlated with moisture and Aw (negative correlations) indicating that higher moisture and Aw promote less browning.

Table 3 depicts CIELab colour for the samples. The positive values of $a *$ and $b *$ indicate that the samples exhibited red and yellow tones. All the parameters ( $a^{*}, b^{*}, L^{*}$ and $E$ ) showed significant differences between the two types of panela, with the darker colours in the block samples if measures were taken from the outside of the block. In contrast, if colour was measured in block panela after it was grated, gradually darker colours in the granulated samples were observed. These findings demonstrated the stratification of the colour in the block samples, where the outer part becomes dark in a greater extent compared to the inner part. Asikin et al. (2016) reported values ranging between 6.33 and $7.47\left(\mathrm{a}^{*}\right), 17.15-20.01$ (b*) for noncentrifugal brown sugar, close to the parameters observed in the present study for granulated samples. However, the $L^{*}$ values $(26.26-35.61)$ obtained by these authors are very low compared to those obtained in the present study. Similar results have also been described by Lee et al. (2018).

Significant correlations were found between browning and $a^{*}, b^{*}, L^{*}$ and $E$, regardless the block samples were or not grated. If granulated panela and original block panela were correlated, the strongest correlation with browning was exhibited by the parameter $a^{*}(r=0.5941, p=0.0001)$, which means that browning is associated with the presence of the red colour. Therefore, in this case, $a^{*}$ would be the parameter that best represents the degree of browning. However, when block samples were grated, browning was mostly correlated with $E(r=-0.6698, p<0.000 I)$ and $L^{*}(r=-0.6420, p<0.000 I)$. In this case, the higher browning was related to a lower luminosity. Colour of panela is the result of the formation of red-brown coloured compounds that turns darker at more intense heating process (Generoso et al., 2009). However, the oxidation of phenolic compounds also contribute to the colour of panela (Fogliano, Monti, Musella, Randazzo, \& Ritieni, 1999). Likewise, Asikin et al. (2016) confirmed that the formation of dark-coloured pigment compounds is enhanced by the increase of temperature used during the heating process. 
Regarding acrylamide, both granulated with not grated and granulated with grated block samples were significantly correlated with $a^{*}(r=0.4006, p=0.0104$ and $r=0.4342, p=0.005 \mathrm{I}$, respectively). This finding conclude that acrylamide formation is related to the development of colour in panela, and more precisely the chromatic parameter $\mathrm{a}^{*}$ could be used as an indirect index of the acrylamide content in panela. Recently, Mesías, Delgado-Andrade, Holgado, and Morales (2018) reported a strong correlation between a* values and acrylamide content in French fries, confirming that the chromatic parameter $\mathrm{a}^{*}$ is able to discriminate between the samples with high and low acrylamide content. In agreement with these authors and in a similar way to the browning, parameter $\mathrm{a}^{*}$ could be selected as the best parameter to predict the acrylamide content in panela samples.

On the other hand, inverse and significant $(p<0.05)$ correlations were observed between HMF and furfural with the colour parameters $\left(L^{*}, a^{*}, b^{*}\right.$ and $\left.E^{*}\right)$, except between HMF and $a^{*}$. Rufián-Henares, GarcíaVillanova, and Guerra-Hernández (2004) described that the advance in non-enzymatic browning in infant/enteral formula-resembling systems was associated with an increase of $a^{*}$ and $b^{*}$ parameters and the colour formation with a consumption of intermediate products of non-enzymatic browning such as HMF and furfural. The inverse correlation detected in the present study corroborates that statement.

\subsection{Total phenolic content (TPC) and antioxidant activity}

The antioxidant capacity showed values between 12.7 and $50.5 \mu \mathrm{mol}$ Trolox equivalents (TEAC)/g (Table 4), without significant differences among granulated and block panela $(p>0.05)$. A similar trend was observed in the TPC, with values that ranged between 1.1 and $6.2 \mathrm{mg}$ of gallic acid equivalent (GAE)/g. A significant correlation was found between both parameters $(r=0.8504, p<0.05)$, in agreement with the results showed by Payet, Sing, and Smadja (2005) ( $r=0.894)$. Similar levels have been reported by Asikin et al. (2016, Asikin et al., 2017) in the antioxidant capacity and TPC in non-centrifugal cane sugar. Lower values in TPC $(0.26 \mathrm{mg}$ GAE/g) have been described by Payet et al. (2005) and much higher values (I65-32I mg GAE/g) by Lee et al. (2018). These differences may be due to the varieties of cane used, to the panela process, to the antioxidant extraction methods and to the measurement protocol used. According to Payet et al. (2005), antioxidative phenolics and flavonoids from the sugarcane stalk are retained in the brown sugar during the noncentrifugation procedure. The high temperatures applied in the evaporation process promote the nonenzymatic browning reactions, the formation of dark-coloured substances but also the accessibility of phenolic compounds entrapped in complex structures (Asikin et al., 2016). This fact would explain the significant correlation exhibited on the one hand between both TPC $(r=0.6326, p<0.000 I)$ and ABTS $(r=0.6266, p<0.0001)$ with the absorbance at $420 \mathrm{~nm}$ and, on the other hand, between TPC and nonenzymatic browning reaction products (acrylamide $(r=0.4078, p=0.0090)$ and furfural $(r=0.3604, p=0.0223)$. The contribution of the non-enzymatic browning reaction products into the antioxidant properties cannot be discarded (Horszwald, Morales, Del Castillo, \& Zieliński, 20I0).

\subsection{Multivariate analysis}

Three principal components (PCs) were obtained considering the acrylamide content, $\mathrm{pH}$, moisture, HMF and furfural content, antioxidant capacity (ABTS), total fenolic content, colour ( $\mathrm{L}^{*}, \mathrm{a}^{*}$ and $\left.\mathrm{b}^{*}\right)$ and browning. It is noteworthy to mention that the colour parameters used for block panela samples in the PCA were those from grated samples in order to be consistent with the rest of the analysis. PCs explain $69.6 \%$ of total variance with $35.9,21.1$ and $12.7 \%$ of the total variance explained by $\mathrm{PCl}, \mathrm{PC} 2$, and PC3, respectively. Fig. I shows the biplot of panela samples and variables. 
$\mathrm{PCl}$ is mainly influenced by $\mathrm{L}^{*}, \mathrm{a}^{*}$, browning $(420 \mathrm{~nm}), \mathrm{ABTS}$ and TPC. $\mathrm{L}^{*}$ exhibited a direct relationship with $\mathrm{PCl}$, while $\mathrm{a}^{*}$, browning $(420 \mathrm{~nm}), \mathrm{ABTS}$ and TPC showed an inverse relation. Likewise, PC2 is primarily characterised by ABTS, TPC, HMF, and furfural. All the variables exhibited a direct association with PC2. Similarly, PC3 is mainly influenced by $a^{*}, b^{*}$, acrylamide, and $\mathrm{pH}$. Acrylamide, $\mathrm{a}^{*}$ and $\mathrm{b}^{*}$ exhibited a directly proportional relation with $\mathrm{PC} 3$, while those in $\mathrm{pH}$ exhibited were inverse.

PCA confirms the existing statistical correlations between the variables and the model. Additionally, when samples are grouped according to the type of panela presentations the variability of the results is explained with a smaller number of variables. Thus, $\mathrm{PCI}$ could indicate the relation of the decrease in the luminosity $\left(\mathrm{L}^{*}\right)$ and the increase of reddish colour $\left(\mathrm{a}^{*}\right)$ with the advanced non-enzymatic browning reaction products as melanoidins which have been reported to increase the antioxidant activity (Contreras-Calderón et al., 2016). PC2 could be seen as the relation of compounds from intermediate stages of nonenzymatic browning reaction with the antioxidant activity since it has been shown that some non-enzymatic browning intermediates have antioxidant activity, as is the case with HMF (Singhara, Macku, \& Shibamoto, 1998). Finally, $\mathrm{PC} 3$ could be interpreted as the influence of the $\mathrm{pH}$ on the acrylamide and colour formation.

CA was performed based on the PCA. Fig. 2 shows the distribution of samples inside the clusters according to $\mathrm{PCl}$ and $\mathrm{PC2}$, in which three clusters were formed. Granulated samples were grouped in clusters II and III, which mainly differs in the antioxidant capacity, HMF, furfural, acrylamide, and browning (420 nm). Cluster III exhibited a greater advance in non-enzymatic browning and a greater antioxidant activity than cluster II. This shows that granulated samples displayed great variability in the indicators analysed, which could be due to differences in the manufacturing process and raw materials used. On the other hand, block panela samples were all grouped in cluster I, except one of them, which was in cluster II. These samples exhibited the highest mean value for L*, b*, HMF and furfural; the lowest mean values for $\mathrm{a}^{*}$, acrylamide and browning (420 nm); and intermediate mean values for Folin and ABTS. CA suggested that the technological process applied to the panela (block and granulated) not only influences the overall quality of final products, but also the acrylamide content.

\section{CONCLUSIONS}

The variability observed in the acrylamide and other heat-induced compounds as well as physicochemical and antioxidant parameters in panela points out the elaboration of this product is poorly standardized and linked to an artisanal elaboration. Granulated panela showed the highest acrylamide content as compared with block panela, in line with the intense dehydration and lower moisture content in the final product. HMF and furfural contents exhibited the same behaviour, being the average content lower in granulated samples as compared to block panela. On the contrary, higher coloured compound levels were found in the group of granulated panela. Lower HMF and furfural concentrations and greater browning suggest the advance of the non-enzymatic browning reaction associated to longer heat treatments together with the possible volatilisation during beating of granulated panela. Then, monitoring the critical points during the process to convert sugarcane juice into panela would help to control the formation of process contaminants. PCA and CA showed an important relationship between the type of panela presentation (granulated or block) and the concentration of the analysed compounds. According to this finding, the type of final presentation should be considered as key factor in the establishment of benchmark levels for panela products. The values of 812 $\mu \mathrm{g} / \mathrm{kg}$ (granulated panela) and $540 \mu \mathrm{g} / \mathrm{kg}$ (block panela) could be settled as preliminary indicative values for the implementation of mitigation strategies in the panela sector. These results are also valuable for regulatory bodies to conclude an accurate risk evaluation of the dietary exposition to acrylamide. 


\section{FUNDING}

This research was cofunded by the Spanish National Research Council (CSIC) (Spain) under project iCOOP (COOPB20288) and the Comunidad of Madrid and European funding from FSE and FEDER programs (project S2018/BAA-4393, AVANSECAL-II-CM).

\section{DECLARATION OF COMPETING INTEREST}

The authors declare that they have no known competing financial interests or personal relationships that could have appeared to influence the work reported in this paper.

\section{ACKNOWLEDGEMENTS}

The authors thank to companies Cooperativa Agraria Norandino Ltda. (Peru) and Doble A Agroindustrias SAS (Colombia).

\section{Appendix A. Supplementary data}

Supplementary data to this article can be found online at https://doi.org//0.1016/j.foodchem.2019.125256.

\section{REFERENCES}

AOAC (1999). Official method of analysis of AOAC Intl (16th ed.). Maryland: Association of Official Analytical Chemists. Asikin, Y., Hirose, N., Tamaki, H., Ito, S., Oku, H., \& Wada, K. (2016). Effects of different drying-solidification processes on physical properties, volatile fraction, and antioxidant activity of non-centrifugal cane brown sugar. LWT - Food Science and Technology, 66, 340-347. https://doi.org/10.1016/j.lwt.2015.10.039.

Asikin, Y., Kamiya, A., Mizu, M., Takara, K., Tamaki, H., \& Wada, K. (20l4). Changes in the physicochemical characteristics, including flavour components and Maillard reaction products, of non-centrifugal cane brown sugar during storage. Food Chemistry, 149, 170-177. https://doi.org// 0.1016/j.foodchem.2013.10.089.

Asikin, Y., Takahara, W., Takahashi, M., Hirose, N., Ito, S., \& Wada, K. (2017). Compositional and electronic discrimination analyses of taste and aroma profiles of non-centrifugal cane brown sugars. Food Analytical Methods, 10, 1844-1856. https://doi.org/10.1007/s 12161-016-0746-5.

Cämmerer, B., Wedzicha, B. L., \& Kroh, L. W. (1999). Nonenzymatic browning reactions of retro.aldol degradation products of carbohydrates. European Food Research \& Technology, 209, 26I-265. https://doi.org//0.1007/s002170050490.

Capuano, E., \& Fogliano, V. (20II). Acrylamide and 5-hydroxymethylfurfural (HMF): A review on metabolism, toxicity, occurrence in food and mitigation strategies. LWT -Food Science and Technology, 44, 793-810. https://doi.org//0.1016/j.Iwt.2010.11.002.

Contreras-Calderón, J., Mejía-Díaz, D., Martínez-Castaño, M., Bedoya-Ramírez, D., López-Rojas, N., GómezNarváez, F., Medina-Pineda, Y., \& Vega-Castro, O. (2016). Evaluation of antioxidant capacity in coffees marketed in Colombia: Relationship with the extent of non-enzymatic browning. Food Chemistry, 209, $162-$ 170. https://doi.org//0.1016/j.foodchem.2016.04.038.

Durán-Castro, N. (2010). Reingeniería panelera (Ist ed.). Tunja: Buhos Editores ISBN: 978-958-44-7577-0.

EFSA (2005). Opinion of the scientific panel on food additives, flavourings, processing aids and materials in contact with food (AFC) on a request from the commission related to flavouring group evaluation 13: 
Furfuryl and furan derivatives with and without additional side-chain. EFSA Journal, 2/5, I-73. https://doi.org// 0.2903/j.efsa.2005.215.

EFSA (2015). Scientific Opinion on acrylamide in food. EFSA Journal, 13(6), 4/04. https://doi.org/10.2903/j.efsa.2015.4104.

European Commission. (2017). COMMISSION REGULATION (EU) 2017/2158 of 20 November 2017 establishing mitigation measures and benchmark levels for the reduction of the presence of acrylamide in food. Official Journal of the European Union, L304, 24-44. http://data.europa.eu/eli/reg/2017/2 158/oj.

Fogliano, V., Monti, S. M., Musella, T., Randazzo, G., \& Ritieni, A. (1999). Formation of coloured Maillard reaction products in a gluten-glucose model system. Food Chemistry, 66, 293-299. https://doi.org/10.1016/S0308-8I46(99)00058-8.

Generoso, W. C., Borges, M. T., Ceccato-Antonini, S. R., Marino, A. F., Silva, M. V., Nassu, R. T., \& VerrumaBernardi, M. R. (2009). Avaliação microbiológica e físico-química de açúcares mascavo comerciais Physicalchemical and microbiological evaluation of commercial brown sugar. Journal of the Adolfo Lutz Institute, 68(2), 259-268. https://doi.org//0.1587I/I5I7-8595/rbpa.vI6n2pl55-162.

Guerra, M. J., \& Mujica, M. A. (2010). Physical and chemical properties of granulated cane sugar "panelas". Ciência e Tecnologia de Alimentos, 3I (I), 250-257.

Hoenicke, K., \& Gatermann, R. (2005). Studies on the Stability of acrylamide in food during storage. Journal of AOAC International, 88, 268-273.

Horszwald, A., Morales, F. J., Del Castillo, M. D., \& Zieliński, H. (20I0). Evaluation ofantioxidant capacity and formation of processing contaminants during rye bread making. Journal of Food and Nutrition Research, 49, 149-159.

INS. (2012). Concepto científico acrilamida en panela. Ministerio de Salud y Protección Social, República de Colombia. https://www.minsalud.gov.co/sites/rid/Lists/BibliotecaDigital/RIDE/IA/INS/Concepto-acrilamidapanela.pdf.

Invima (National Institute of Drug and Foods Vigilance) (2018). Informe de resultados del plan nacional sobsectorial de vigilancia y control de acrilamida en alimentos procesados durante los años 2015-2016. Gobierno de Colombia. https://www.invima.gov.co/images/pdf/INFORMESALIMENTOS/INFORMEACRILAMIDA.pdf.

Jaffé, W. R. (2012). Health effects of non-centrifugal sugar (NCS): A review. Sugar Tech, 14, 87-94. https://doi.org//0.1007/s I2355-012-0145-I.

Jaffé, W. R. (2015). Nutritional and functional components of non centrifugal cane sugar: A compilation of the data from the analytical literature. Journal of Food Composition and Analysis, 43, 194-202. https://doi.org/10.1016/j.jfca.2015.06.007.

Kroh, L. W. (1994). Caramelisation in food and beverages. Food Chemistry, 5I, 373-379. https://doi.org//0.1016/0308-8/46(94)90188-0. 
La Madrid, R., Mendoza Orbegoso, E., Saavedra, R., \& Marcelo, D. (2017). Improving the thermal efficiency of a jaggery production module using a fire-tube heat exchanger. Journal of Environmental Management, 204, 622-636. https://doi.org/10.1016/j.jenvman.2017.09.035.

Lee, J. S., Ramalingam, S., Jo, I. G., Kwon, Y. S., Bahuguna, A., Oh, Y. S., ... Kim, M. (2018). Comparative study of the physicochemical, nutritional, and antioxidant properties of some commercial refined and noncentrifugal sugars. Food Research International, 109, 614-625. https://doi.org// 0.1016/j.foodres.2018.04.047.

Marfil, R., Giménez, R., Martínez, O., Bouzas, P. R., Rufián-Henares, J. A., Mesías, M., \& Cabrera-Vique, C. (20II). Determination of polyphenols, tocopherols, and antioxidant capacity in virgin argan oil (Argania spinosa, Skeels). European Journal of Lipid Science and Technology, II3, 886-893. https://doi.org// 0.1002/ejlt.201000503.

Mesías, M., \& Delgado-Andrade, C. (2017). Melanoidins as a potential functional food ingredient. Current Opinion in Food Science, 14, 37-42. https://doi.org/I0.1016/j.cofs.2017.01.007.

Mesías, M., Delgado-Andrade, C., Holgado, F., \& Morales, F. J. (2018). Acrylamide content in French fries prepared in households. A pilot study in Spanish homes. Food Chemistry, 260, 44-52. https://doi.org/10.1016/j.foodchem.2018.03.140.

Mesías, M., Holgado, F., Márquez-Ruíz, G., \& Morales, F. J. (2015). Effect of sodium replacement in cookies on the formation of process contaminants and lipid oxidation. LWT - Food Science and Technology, 62, 633-639. https://doi.org/10.1016/J.LWT.2014.11.028.

Mesías, M., \& Morales, F. J. (2015). Acrylamide in commercial potato crisps from Spanish market: Trends from 2004 to 2014 and assessment of the dietary exposure. Food and Chemical Toxicology, 8I, 104-1 10. https://doi.org//0.1016/j.fct.2015.03.03I.

Mujica, M. V., Guerra, M., \& Soto, N. (2008). Efecto de la variedad, lavado de la caña y temperatura de punteo sobre la calidad de la panela granulada. Interciencia, 33, 598-602.

Payet, B., Sing, A. S. C., \& Smadja, J. (2005). Assessment of antioxidant activity of cane brown sugars by $A B T S$ and DPPH radical scavenging assays: Determination of their polyphenolic and volatile constituents. Journal of Agricultural and Food Chemistry, 53, I0074-10079. https://doi.org/I0.102 I/jf05 I7703.

Pérez-Jiménez, J., \& Saura-Calixto, F. (2005). Literature data may underestimate the actual antioxidant capacity of cereals. Journal of Agricultural and Food Chemistry, 53, 5036-5040. https://doi.org// 0.102I/jf050049u.

Rufián-Henares, J. A., \& Delgado-Andrade, C. (2009). Effect of digestive process on Maillard reaction indexes and antioxidant properties of breakfast cereals. Food Research International, 42, 394-400. https://doi.org/10.1016/j.foodres.2009.01.011.

Rufián-Henares, J., García-Villanova, B., \& Guerra-Hernández, E. (2004). Generation of furosine and color in infant/enteral formula-resembling systems. Journal of Agricultural and Food Chemistry, 52, 5354-5358. https://doi.org// 0.1021/jf040088q.

Sachse, B., Meinl, W., Sommer, Y., Glatt, H., Seidel, A., \& Monien, B. H. (2016). Bioactivation of food genotoxicants 5 -hydroxymethylfurfural and furfuryl alcohol by sulfotransferases from human, mouse and rat: A comparative study. Archives of Toxicology, 90, I37-I48. https://doi.org//0.1007/s00204-0 I4-I392-6. 
Silva, P., Silva, C. L., Perestrelo, R., Nunes, F. M., \& Câmara, J. S. (2018). Fingerprint targeted compounds in authenticity of sugarcane honey-An approach based on chromatographic and statistical data. Lwt, 96(April), 82-89. https://doi.org/10.1016/j.Iwt.2018.04.076.

Singhara, A., Macku, C., Shibamoto, T. (1998). Antioxidative activity of brewed coffee extracts. Functional Foods for Disease Prevention II: Medicinal Plants and Other F (PP 10I-109). Washington, D. C.: ACS Symposium Series 701 .

Svendsen, C., Husøy, T., Glatt, H., Paulsen, J. E., \& Alexander, J. (2009). 5-Hydroxymethylfurfural and 5sulfooxymethylfurfural increase adenoma and flat ACF number in the intestine of Min/+ mice. Anticancer Research, 29, 1921-1926.

Takara, K., Matsui, D., Wada, K., Ichiba, T., \& Nakasone, Y. (2002). New antioxidative phenolic glycosides isolated from Kokuto non-centrifuged cane sugar. Bioscience, Biotechnology, and Biochemistry, 66, 29-35. https://doi.org// 0.127I/bbb.66.29.

Vargas Lasso, J. J., Talero Pérez, Y. V., Trujillo Suárez, F. A., \& Caballero, L. R. (2014). Determinación de acrilamida en el procesamiento de la panela por cromatografía líquida Acrylamide Determintion in the Sugar Cane Juice Process by the Liquid Chromatography Technique. Revista Ciencia En Desarrollo, 5, 99-105. https://doi.org/I0.19053/0I2I7488.3664.

Wen, C., Shi, X., Wang, Z., Gao, W., Jiang, L., Xiao, Q., Deng, F. (2016). Effects of metal ions on formation of acrylamide and 5-hydroxymethylfurfural in asparagine-glucose model system. International journal of Food Science and Technology, 5I, 279-285. https://doi.org/I0.I I I I/ijfs. 12966. 
FIGURES AND TABLES

Table I. Moisture, Aw and $\mathrm{pH}$ of panela samples.

\begin{tabular}{|c|c|c|c|c|}
\hline Sample & $\begin{array}{l}\text { Place of } \\
\text { purchase }\end{array}$ & Moisture (\%) & $A w$ & $\mathrm{pH}$ \\
\hline \multicolumn{5}{|c|}{ Granulated } \\
\hline I & Italy & $2.9 \pm 0.0$ & $0.54 \pm 0.00$ & $5.8 \pm 0.0$ \\
\hline 2 & Italy & $3.1 \pm 0.2$ & $0.52 \pm 0.00$ & $5.9 \pm 0.0$ \\
\hline 3 & Italy & $3.8 \pm 0.1$ & $0.58 \pm 0.00$ & $6.1 \pm 0.0$ \\
\hline 4 & Italy & $3.9 \pm 0.1$ & $0.51 \pm 0.00$ & $6.2 \pm 0.0$ \\
\hline 5 & Italy & $4.2 \pm 0.2$ & $0.51 \pm 0.00$ & $6.5 \pm 0.2$ \\
\hline 6 & Peru & $3.3 \pm 0.0$ & $0.66 \pm 0.02$ & $6.5 \pm 0.0$ \\
\hline 7 & Peru & $2.5 \pm 0.0$ & $0.52 \pm 0.01$ & $6.6 \pm 0.1$ \\
\hline 8 & Peru & $2.0 \pm 0.0$ & $0.60 \pm 0.03$ & $6.6 \pm 0.1$ \\
\hline 9 & Peru & $4.9 \pm 0.0$ & $0.62 \pm 0.00$ & $6.0 \pm 0.0$ \\
\hline 10 & Spain & $0.8 \pm 0.0$ & $0.48 \pm 0.01$ & $5.5 \pm 0.0$ \\
\hline 11 & Spain & $2.9 \pm 0.0$ & $0.50 \pm 0.00$ & $5.9 \pm 0.0$ \\
\hline 12 & Spain & $2.4 \pm 0.1$ & $0.5 \mathrm{I} \pm 0.00$ & $5.8 \pm 0.0$ \\
\hline 13 & Spain & $3.2 \pm 0.1$ & $0.57 \pm 0.00$ & $5.3 \pm 0.0$ \\
\hline 14 & Spain & $3.1 \pm 0.0$ & $0.54 \pm 0.00$ & $5.7 \pm 0.0$ \\
\hline 15 & Spain & $3.1 \pm 0.1$ & $0.61 \pm 0.01$ & $6.0 \pm 0.0$ \\
\hline 16 & Spain & $1.7 \pm 0.0$ & $0.44 \pm 0.00$ & $5.9 \pm 0.0$ \\
\hline 17 & Spain & $0.6 \pm 0.0$ & $0.43 \pm 0.01$ & $5.6 \pm 0.1$ \\
\hline 18 & Spain & $5.3 \pm 0.1$ & $0.56 \pm 0.00$ & $6.1 \pm 0.0$ \\
\hline 19 & Spain & $3.2 \pm 0.0$ & $0.49 \pm 0.00$ & $6.4 \pm 0.0$ \\
\hline 20 & Spain & $2.9 \pm 0.2$ & $0.47 \pm 0.00$ & $6.0 \pm 0.0$ \\
\hline 21 & Spain & $3.4 \pm 0.2$ & $0.53 \pm 0.00$ & $7.1 \pm 0.1$ \\
\hline 22 & Spain & $2.8 \pm 0.1$ & $0.37 \pm 0.00$ & $5.7 \pm 0.0$ \\
\hline 23 & Spain & $3.8 \pm 0.1$ & $0.47 \pm 0.00$ & $5.9 \pm 0.0$ \\
\hline 24 & Spain & $4.5 \pm 0.1$ & $0.50 \pm 0.00$ & $6.4 \pm 0.0$ \\
\hline Mean & & $3.1 \pm 1.1^{\mathrm{a}}$ & $0.52 \pm 0.06^{\mathrm{a}}$ & $6.1 \pm 0.4^{b}$ \\
\hline \multicolumn{5}{|l|}{ Block } \\
\hline 25 & Colombia & $9.5 \pm 0.3$ & $0.66 \pm 0.02$ & $5.9 \pm 0.0$ \\
\hline 26 & Colombia & $9.4 \pm 0.5$ & $0.69 \pm 0.03$ & $5.7 \pm 0.0$ \\
\hline 27 & Colombia & $9.4 \pm 0.5$ & $0.74 \pm 0.02$ & $5.8 \pm 0.0$ \\
\hline 28 & Colombia & $9.1 \pm 0.1$ & $0.73 \pm 0.05$ & $6.0 \pm 0.1$ \\
\hline 29 & Colombia & $8.4 \pm 0.2$ & $0.69 \pm 0.04$ & $6.0 \pm 0.0$ \\
\hline 30 & Colombia & $9.6 \pm 0.1$ & $0.7 \mathrm{I} \pm 0.02$ & $5.9 \pm 0.0$ \\
\hline 31 & Colombia & $9.2 \pm 0.1$ & $0.74 \pm 0.02$ & $5.8 \pm 0.1$ \\
\hline 32 & Colombia & $7.9 \pm 0.3$ & $0.73 \pm 0.03$ & $5.9 \pm 0.0$ \\
\hline 33 & Colombia & $8.0 \pm 0.1$ & $0.71 \pm 0.02$ & $5.8 \pm 0.0$ \\
\hline 34 & Colombia & $7.8 \pm 0.1$ & $0.68 \pm 0.02$ & $6.0 \pm 0.0$ \\
\hline 35 & Colombia & $7.8 \pm 0.1$ & $0.71 \pm 0.02$ & $6.0 \pm 0.1$ \\
\hline 36 & Colombia & $8.7 \pm 0.1$ & $0.71 \pm 0.03$ & $5.9 \pm 0.0$ \\
\hline 37 & Colombia & $8.4 \pm 0.1$ & $0.70 \pm 0.01$ & $6.0 \pm 0.0$ \\
\hline 38 & Colombia & $10.0 \pm 0.4$ & $0.70 \pm 0.02$ & $5.9 \pm 0.1$ \\
\hline 39 & Colombia & $8.6 \pm 0.1$ & $0.70 \pm 0.02$ & $5.9 \pm 0.0$ \\
\hline 40 & Colombia & $7.6 \pm 0.0$ & $0.64 \pm 0.04$ & $6.0 \pm 0.1$ \\
\hline Mean & & $8.7 \pm 0.8^{b}$ & $0.70 \pm 0.03^{b}$ & $5.9 \pm 0 . I^{a}$ \\
\hline
\end{tabular}

Aw: water activity. Results are expressed as mean \pm standard deviation $(n=2)$. Different superscripts in the same column indicate significant $(\mathrm{p}<0.05)$ differences. 
Table 2. Acrylamide, HMF, furfural and browning of panela samples.

\begin{tabular}{cllll}
\hline Sample & $\begin{array}{l}\text { Acrylamide } \\
(\mu \mathrm{g} / \mathrm{kg})\end{array}$ & $\begin{array}{l}\mathrm{HMF} \\
(\mathrm{mg} / \mathrm{kg})\end{array}$ & $\begin{array}{l}\text { Furfural } \\
(\mathrm{mg} / \mathrm{kg})\end{array}$ & $\begin{array}{l}\text { Abs 420 } \\
\text { (units/g) }\end{array}$ \\
\hline Granulated & & & & \\
1 & $945 \pm 2$ & $6.5 \pm 0.0$ & $1.7 \pm 0.0$ & $8.4 \pm 0.2$ \\
2 & $60 \pm 5$ & $0.9 \pm 0.1$ & $1.9 \pm 0.1$ & $2.3 \pm 0.0$ \\
3 & $2632 \pm 1 \mathrm{II}$ & $4.0 \pm 0.2$ & $2.0 \pm 0.0$ & $6.4 \pm 0.1$ \\
4 & $1099 \pm 8$ & $10.4 \pm 0.1$ & $2.0 \pm 0.0$ & $6.1 \pm 0.1$ \\
5 & $155 \pm 7$ & $7.9 \pm 0.1$ & $2.5 \pm 0.0$ & $7.2 \pm 0.2$ \\
6 & $815 \pm 8$ & $1.5 \pm 0.0$ & $<\mathrm{LOQ}$ & $3.0 \pm 0.1$ \\
7 & $62 \pm 1$ & $5.8 \pm 0.4$ & $<\mathrm{LOQ}$ & $3.5 \pm 0.1$ \\
8 & $360 \pm 0$ & $<\mathrm{LOQ}$ & $<\mathrm{LOQ}$ & $2.3 \pm 0.1$ \\
9 & $503 \pm 9$ & $<\mathrm{LOQ}$ & $2.1 \pm 0.20$ & $7.1 \pm 0.1$ \\
10 & $412 \pm 22$ & $<\mathrm{LOQ}$ & $1.4 \pm 0.1$ & $2.7 \pm 0.1$ \\
11 & $764 \pm 7$ & $3.1 \pm 0.1$ & $2.3 \pm 0.0$ & $4.4 \pm 0.1$ \\
12 & $398 \pm 2$ & $1.0 \pm 0.0$ & $1.7 \pm 0.1$ & $3.9 \pm 0.0$ \\
13 & $133 \pm 4$ & $1.5 \pm 0.1$ & $0.6 \pm 0.0$ & $5.2 \pm 0.1$ \\
14 & $456 \pm 2$ & $0.9 \pm 0.0$ & $<\mathrm{LOQ}$ & $6.1 \pm 0.1$ \\
15 & $187 \pm 25$ & $2.0 \pm 0.0$ & $0.3 \pm 0.1$ & $4.3 \pm 0.0$ \\
16 & $407 \pm 5$ & $<\mathrm{LOQ}$ & $<\mathrm{LOQ}$ & $2.4 \pm 0.0$ \\
17 & $730 \pm 18$ & $1.6 \pm 0.2$ & $0.6 \pm 0.0$ & $11.5 \pm 0.2$ \\
18 & $1427 \pm 35$ & $6.7 \pm 0.0$ & $2.7 \pm 0.0$ & $5.4 \pm 0.1$ \\
19 & $663 \pm 35$ & $4.6 \pm 0.2$ & $2.5 \pm 0.0$ & $5.5 \pm 0.1$ \\
20 & $723 \pm 16$ & $1.7 \pm 0.0$ & $1.2 \pm 0.0$ & $4.5 \pm 0.0$ \\
21 & $895 \pm 0$ & $4.6 \pm 0.0$ & $2.4 \pm 0.0$ & $7.8 \pm 0.1$ \\
22 & $3058 \pm 11$ & $8.3 \pm 0.1$ & $3.1 \pm 0.1$ & $7.5 \pm 0.1$ \\
23 & $1314 \pm 3$ & $1.3 \pm 0.0$ & $2.0 \pm 0.1$ & $3.9 \pm 0.1$ \\
24 & $1280 \pm 9$ & $1.7 \pm 0.1$ & $2.1 \pm 0.0$ & $3.9 \pm 0.1$ \\
\hline Mean & $812 \pm 743^{\mathrm{a}}$ & $3.2 \pm 2.9^{\mathrm{a}}$ & $1.5 \pm 1.0^{\mathrm{a}}$ & $5.2 \pm 2.3^{\mathrm{b}}$ \\
\hline & & & & \\
\hline 10 & & & &
\end{tabular}

\begin{tabular}{lllll}
\hline Block & & & & \\
25 & $414 \pm 7$ & $9.7 \pm 1.0$ & $<$ LOQ & $3.0 \pm 0.0$ \\
26 & $664 \pm 51$ & $4.7 \pm 0.1$ & $<$ LOQ & $2.1 \pm 0.0$ \\
27 & $505 \pm 36$ & $<\mathrm{LOQ}$ & $3.0 \pm 0.0$ & $1.5 \pm 0.1$ \\
28 & $259 \pm 1$ & $4.1 \pm 0.2$ & $4.0 \pm 0.4$ & $1.7 \pm 0.0$ \\
29 & $558 \pm 1$ & $9.1 \pm 0.4$ & $3.2 \pm 0.1$ & $2.2 \pm 0.0$ \\
30 & $285 \pm 5$ & $1.9 \pm 0.0$ & $3.4 \pm 0.2$ & $2.0 \pm 0.0$ \\
31 & $825 \pm 17$ & $0.4 \pm 0.0$ & $2.7 \pm 0.2$ & $1.8 \pm 0.1$ \\
32 & $381 \pm 18$ & $1.4 \pm 0.1$ & $3.2 \pm 0.3$ & $2.1 \pm 0.0$ \\
33 & $881 \pm 14$ & $2.9 \pm 0.0$ & $3.0 \pm 0.1$ & $2.3 \pm 0.1$ \\
34 & $654 \pm 5$ & $14.8 \pm 1.1$ & $3.4 \pm 0.2$ & $2.5 \pm 0.1$ \\
35 & $590 \pm 17$ & $5.9 \pm 0.5$ & $2.6 \pm 0.3$ & $2.0 \pm 0.1$ \\
36 & $317 \pm 7$ & $12.3 \pm 0.8$ & $3.9 \pm 0.4$ & $2.0 \pm 0.1$ \\
37 & $510 \pm 11$ & $3.3 \pm 0.3$ & $3.6 \pm 0.0$ & $2.2 \pm 0.1$ \\
38 & $290 \pm 8$ & $11.0 \pm 0.1$ & $3.8 \pm 0.1$ & $2.1 \pm 0.1$ \\
39 & $619 \pm 51$ & $4.9 \pm 0.4$ & $2.9 \pm 0.2$ & $1.9 \pm 0.1$ \\
40 & $890 \pm 15$ & $2.4 \pm 0.2$ & $4.5 \pm 0.8$ & $3.6 \pm 0.1$ \\
\hline Mean & $540 \pm 209^{\mathrm{a}}$ & $5.9 \pm 4.4^{\mathrm{b}}$ & $3.0 \pm 1.2^{\mathrm{b}}$ & $2.2 \pm 0.5^{\mathrm{a}}$ \\
\hline
\end{tabular}

LOQ: Limit of quantification. Results are expressed as mean \pm standard deviation $(n=2)$. Different superscripts in the same column indicate significant $(p<0.05)$ differences. 
Table 3. Colour parameters of panela samples (granulated, outer part of the block (not grated) and grated block).

\begin{tabular}{|c|c|c|c|c|c|c|c|c|}
\hline Sample & \multicolumn{2}{|c|}{$L^{*}$} & \multicolumn{2}{|c|}{$a^{*}$} & & $b^{*}$ & \multicolumn{2}{|c|}{$\mathrm{E}$} \\
\hline \multicolumn{9}{|c|}{ Granulated } \\
\hline I & \multirow{2}{*}{\multicolumn{2}{|c|}{$\begin{array}{l}49.3 \pm 0.2 \\
65.2+1.3\end{array}$}} & \multicolumn{2}{|c|}{$6.7 \pm 0.1$} & \multicolumn{2}{|c|}{$12.5 \pm 0.2$} & \multicolumn{2}{|c|}{$51.3 \pm 0.3$} \\
\hline 2 & & & \multicolumn{2}{|c|}{$5.8 \pm 0.2$} & \multicolumn{2}{|c|}{$21.0 \pm 0.1$} & \multicolumn{2}{|c|}{$68.7 \pm 1.5$} \\
\hline 3 & & \multicolumn{2}{|c|}{$8.6 \pm 0.2$} & \multicolumn{2}{|c|}{$15.4 \pm 0.2$} & \multicolumn{2}{|c|}{$54.2 \pm 0.3$} \\
\hline 4 & \multicolumn{2}{|c|}{$60.8 \pm 0.4$} & \multicolumn{2}{|c|}{$9.3 \pm 0.0$} & \multicolumn{2}{|c|}{$23.2 \pm 0.4$} & \multicolumn{2}{|c|}{$65.7 \pm 0.7$} \\
\hline 5 & \multicolumn{2}{|c|}{$50.8 \pm 0.5$} & \multicolumn{2}{|c|}{$7.5 \pm 0.6$} & \multicolumn{2}{|c|}{$13.0 \pm 1.0$} & & 0.9 \\
\hline 6 & \multicolumn{2}{|c|}{$58.0 \pm 0.8$} & $7.1 \pm$ & & 18 & \pm 0.4 & & $=1.0$ \\
\hline 7 & 50. & \pm 0.3 & $5.6 \pm$ & & & \pm 0.2 & & 0.4 \\
\hline 8 & 57. & \pm 0.4 & $7.3 \pm$ & & 20 & \pm 0.4 & & $=0.7$ \\
\hline 9 & 43. & \pm 0.8 & $5.8 \pm$ & & & \pm 1.1 & & $=1.3$ \\
\hline 10 & 62.8 & \pm 0.1 & $7.3 \pm$ & & & \pm 0.1 & 66 & $=0.1$ \\
\hline $\begin{array}{l}11 \\
12\end{array}$ & $\begin{array}{l}58 . \\
59 .\end{array}$ & $\begin{array}{l} \pm 0.2 \\
\pm 0.6\end{array}$ & $\begin{array}{l}8.9 \pm \\
8.5 \pm\end{array}$ & & & $\begin{array}{l} \pm 0.2 \\
\pm 0.7\end{array}$ & $\begin{array}{l}63 \\
63\end{array}$ & $\begin{array}{l}0.1 \\
0.9\end{array}$ \\
\hline 13 & 63. & \pm 0.3 & $7.2 \pm$ & & 18 & \pm 0.1 & & 0.4 \\
\hline 14 & 63. & \pm 0.3 & $8.1 \pm$ & & & \pm 0.0 & & $=0.4$ \\
\hline 15 & 53. & \pm 0.6 & $7.1 \pm$ & 0.3 & & \pm 0.7 & & 0.9 \\
\hline 16 & 64. & \pm 0.4 & $7.4 \pm$ & & & \pm 0.1 & & $=0.5$ \\
\hline 17 & 47. & \pm 0.4 & $7.3 \pm$ & & & \pm 0.5 & & 0.7 \\
\hline 18 & 59. & \pm 0.8 & $8.1 \pm$ & & & \pm 0.8 & & $=1.3$ \\
\hline 19 & 61.8 & \pm 1.1 & $7.6 \pm$ & & & \pm 0.7 & & $=1.5$ \\
\hline 20 & 56 & \pm 0.2 & $7.7 \pm$ & & & \pm 0.3 & & 0.3 \\
\hline 21 & 57. & \pm 0.4 & $8.7 \pm$ & & & \pm 0.1 & & $=0.5$ \\
\hline 22 & 57. & \pm 0.2 & $9.4 \pm$ & & & \pm 0.1 & & $=0.2$ \\
\hline 23 & 60. & \pm 0.3 & $9.0 \pm$ & & & \pm 0.2 & & $=0.4$ \\
\hline 24 & 60. & \pm 0.4 & $8.7 \pm$ & & & \pm 0.1 & & $=0.5$ \\
\hline Mean & 57. & $\pm 5.8^{\mathrm{bA}}$ & $7.7 \pm$ & $1.1 \mathrm{bB}$ & & $\pm 4.3^{\mathrm{bA}}$ & & $6.6 \mathrm{bA}$ \\
\hline Block & Notgrated & Grated & Notgrated & Grated & Notgrated & Grated & Notgrated & Grated \\
\hline 25 & $45.5 \pm 0.2$ & $66.6 \pm 0.4$ & $6.4 \pm 0.4$ & $7.0 \pm 0.2$ & $10.9 \pm 0.2$ & $26.2 \pm 0.56$ & $47.2 \pm 0.2$ & $72.0 \pm 0.3$ \\
\hline 26 & $45.3 \pm 0.8$ & $63.0 \pm 0.3$ & $4.4 \pm 0.3$ & $7.5 \pm 0.4$ & $8.7 \pm 0.9$ & $25.5 \pm 0.7$ & $46.4 \pm 1.2$ & $68.4 \pm 0.2$ \\
\hline 27 & $43.9 \pm 0.9$ & $69.5 \pm 0.5$ & $3.9 \pm 0.4$ & $4.3 \pm 0.2$ & $7.5 \pm 1.2$ & $21.8 \pm 0.6$ & $44.7 \pm 1.4$ & $73.0 \pm 0.5$ \\
\hline 28 & $47.7 \pm 0.8$ & $76.9 \pm 0.5$ & $4.4 \pm 0.2$ & $3.3 \pm 0.2$ & $11.0 \pm 0.2$ & $21.6 \pm 0.7$ & $49.1 \pm 0.9$ & $80.0 \pm 0.5$ \\
\hline 29 & $42.0 \pm 0.9$ & $69.9 \pm 0.3$ & $3.1 \pm 0.1$ & $4.7 \pm 0.2$ & $5.4 \pm 0.5$ & $23.8 \pm 0.6$ & $42.5 \pm 1.2$ & $74.0 \pm 0.5$ \\
\hline 30 & $44.3 \pm 1.2$ & $58.3 \pm 0.9$ & $4.6 \pm 0.2$ & $8.5 \pm 0.3$ & $9.0 \pm 1.6$ & $25.2 \pm 0.4$ & $45.5 \pm 1.8$ & $64.1 \pm 0.9$ \\
\hline 31 & $46.0 \pm 1.3$ & $57.2 \pm 1.3$ & $4.2 \pm 0.4$ & $6.6 \pm 0.3$ & $9.3 \pm 1.1$ & $21.2 \pm 0.4$ & $47.1 \pm 1.8$ & $61.3 \pm 1.2$ \\
\hline 32 & $46.5 \pm 1.0$ & $72.9 \pm 1.5$ & $3.8 \pm 0.1$ & $4.1 \pm 0.5$ & $8.9 \pm 0.4$ & $20.4 \pm 0.5$ & $47.5 \pm 1.3$ & $75.8 \pm 1.3$ \\
\hline 33 & $45.0 \pm 0.8$ & $61.8 \pm 0.9$ & $3.5 \pm 0.3$ & $6.4 \pm 0.2$ & $6.8 \pm 0.5$ & $22.8 \pm 0.9$ & $45.7 \pm 1.0$ & $66.2 \pm 1.1$ \\
\hline 34 & $45.7 \pm 0.5$ & $77.3 \pm 3.9$ & $5.1 \pm 0.5$ & $2.4 \pm 0.2$ & $8.5 \pm 0.5$ & $18.3 \pm 0.4$ & $46.7 \pm 0.7$ & $79.5 \pm 3.7$ \\
\hline 35 & $43.4 \pm 1.6$ & $67.4 \pm 2.1$ & $2.7 \pm 0.2$ & $6.0 \pm 0.8$ & $6.7 \pm 1.3$ & $24.8 \pm 1.1$ & $44.0 \pm 2.2$ & $72.1 \pm 1.7$ \\
\hline 36 & $43.6 \pm 1.1$ & $67.8 \pm 1.3$ & $4.6 \pm 0.3$ & $5.4 \pm 0.3$ & $7.5 \pm 1.2$ & $25.3 \pm 0.5$ & $44.5 \pm 1.5$ & $72.6 \pm 1.4$ \\
\hline 37 & $45.2 \pm 0.5$ & $64.5 \pm 0.6$ & $5.8 \pm 0.1$ & $6.1 \pm 0.6$ & $9.2 \pm 0.3$ & $23.9 \pm 0.9$ & $46.5 \pm 0.6$ & $69.1 \pm 0.3$ \\
\hline 38 & $43.2 \pm 1.1$ & $56.4 \pm 1.2$ & $4.3 \pm 0.6$ & $8.2 \pm 0.2$ & $6.8 \pm 1.2$ & $22.9 \pm 1.0$ & $43.9 \pm 1.6$ & $61.4 \pm 1.4$ \\
\hline 39 & $43.1 \pm 0.6$ & $59.1 \pm 0.4$ & $4.1 \pm 0.6$ & $6.8 \pm 0.1$ & $6.4 \pm 1.0$ & $22.6 \pm 0.2$ & $43.8 \pm 0.9$ & $63.7 \pm 0.5$ \\
\hline 40 & $4 I .4 \pm 0.4$ & $63.0 \pm 0.5$ & $1.9 \pm 0.1$ & $6.9 \pm 0.1$ & $2.9 \pm 0.3$ & $23.2 \pm 0.1$ & $41.6 \pm 0.5$ & $67.5 \pm 0.4$ \\
\hline Mean & $44.5 \pm 1.7^{a}$ & $65.7 \pm 6.5^{B}$ & $4.2 \pm I . I^{a}$ & $5.9 \pm 1.7 \mathrm{~A}$ & $7.8 \pm 2.0^{a}$ & $23.1 \pm 2.1^{B}$ & $45.4 \pm 2.0^{a}$ & $70.0 \pm 5.8$ \\
\hline
\end{tabular}

Different superscripts in the same column indicate significant $(p<0.05)$ differences. Lowercase involves statistical comparison between granulated and not grated block panelas. Uppercase involves statistical comparison between granulated and grated block panelas. 
Table 4. Antioxidant activity and total phenolic content of panela samples.

\begin{tabular}{|c|c|c|}
\hline Sample & ABTS $(\mu \mathrm{mol}$ TEAC/g) & Total phenolics (mg GAE/g) \\
\hline \multicolumn{3}{|c|}{ Granulated } \\
\hline I & $26.4 \pm 0.7$ & $3.8 \pm 0.1$ \\
\hline 2 & $28.2 \pm 0.7$ & $4.0 \pm 0.1$ \\
\hline 3 & $31.1 \pm 0.3$ & $4.4 \pm 0.0$ \\
\hline 4 & $33.7 \pm 0.7$ & $5.3 \pm 0.0$ \\
\hline 5 & $31.0 \pm 0.6$ & $5.6 \pm 0.1$ \\
\hline 6 & $25.7 \pm 0.2$ & $2.3 \pm 0.2$ \\
\hline 7 & $27.3 \pm 0.3$ & $2.6 \pm 0.1$ \\
\hline 8 & $28.9 \pm 0.3$ & $2.7 \pm 0.2$ \\
\hline 9 & $33.0 \pm 0.3$ & $3.6 \pm 0.1$ \\
\hline 10 & $16.3 \pm 0.5$ & $\mathrm{I} . \mathrm{I} \pm 0.0$ \\
\hline 11 & $28.3 \pm 0.3$ & $4.2 \pm 0.1$ \\
\hline 12 & $25.2 \pm 0.4$ & $3.6 \pm 0.1$ \\
\hline 13 & $20.6 \pm 0.4$ & $3.0 \pm 0.1$ \\
\hline 14 & $23.9 \pm 0.5$ & $3.2 \pm 0.1$ \\
\hline 15 & $18.4 \pm 0.2$ & $2.6 \pm 0.1$ \\
\hline 16 & $22.0 \pm 1.5$ & $3.3 \pm 0.0$ \\
\hline 17 & $12.7 \pm 0.4$ & $1.6 \pm 0.0$ \\
\hline 18 & $50.5 \pm 1.3$ & $6.2 \pm 0.1$ \\
\hline 19 & $33.0 \pm 0.2$ & $4.6 \pm 0.1$ \\
\hline 20 & $36.1 \pm 0.6$ & $5.6 \pm 0.1$ \\
\hline 21 & $34.0 \pm 0.5$ & $4.7 \pm 0.0$ \\
\hline 22 & $37.3 \pm 0.4$ & $5.4 \pm 0.1$ \\
\hline 23 & $47.8 \pm 0.8$ & $5.6 \pm 0.1$ \\
\hline 24 & $31.2 \pm 0.7$ & $5.4 \pm 0.1$ \\
\hline Mean & $29.3 \pm 8.7^{a}$ & $3.9 \pm 1.4^{\mathrm{a}}$ \\
\hline \multicolumn{3}{|l|}{ Block } \\
\hline 25 & $26.6 \pm 1.2$ & $3.5 \pm 0.0$ \\
\hline 26 & $21.7 \pm 0.2$ & $3.0 \pm 0.0$ \\
\hline 27 & $26.4 \pm 1.5$ & $3.4 \pm 0.0$ \\
\hline 28 & $29.7 \pm 0.2$ & $4.2 \pm 0.1$ \\
\hline 29 & $25.2 \pm 0.4$ & $2.7 \pm 0.1$ \\
\hline 30 & $28.1 \pm 0.2$ & $3.9 \pm 0.1$ \\
\hline 31 & $26.6 \pm 1.0$ & $3.6 \pm 0.1$ \\
\hline 32 & $25.7 \pm 0.3$ & $3.6 \pm 0.0$ \\
\hline 33 & $29.5 \pm 0.3$ & $4.1 \pm 0.1$ \\
\hline 34 & $19.9 \pm 0.5$ & $3.3 \pm 0.1$ \\
\hline 35 & $29.3 \pm 0.3$ & $4.0 \pm 0.1$ \\
\hline 36 & $29.7 \pm 0.7$ & $3.7 \pm 0.1$ \\
\hline 37 & $28.2 \pm 0.3$ & $3.8 \pm 0.1$ \\
\hline 38 & $31.2 \pm 0.2$ & $4.4 \pm 0.1$ \\
\hline 39 & $31.5 \pm 0.5$ & $4.1 \pm 0.1$ \\
\hline 40 & $29.7 \pm 0.4$ & $4.2 \pm 0.1$ \\
\hline Mean & $27.4 \pm 3.2^{\mathrm{a}}$ & $3.7 \pm 0.5^{\mathrm{a}}$ \\
\hline
\end{tabular}

TEAC: Equivalent of Trolox. GAE: Gallic acid equivalent. Results are expressed as mean \pm standard deviation $(n=2)$. Different superscripts in the same column indicate significant $(p<0.05)$ differences. 
Figure I. Principal component analysis (PCA) of the panela samples according to acrylamide, $\mathrm{pH}$, moisture, HMF, furfural, antioxidant capacity, TFC, colour and browning. Figures a (PC2 vs. PCI), b (PC3 vs. PCI) and c (PC3 vs. PC2) represent different views of the same plot.

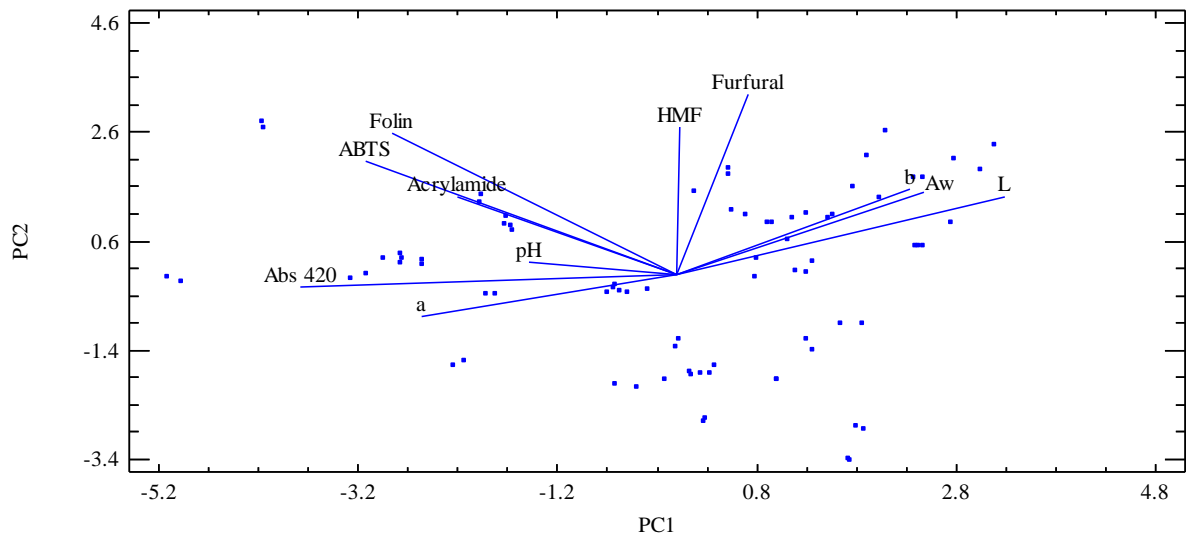

a

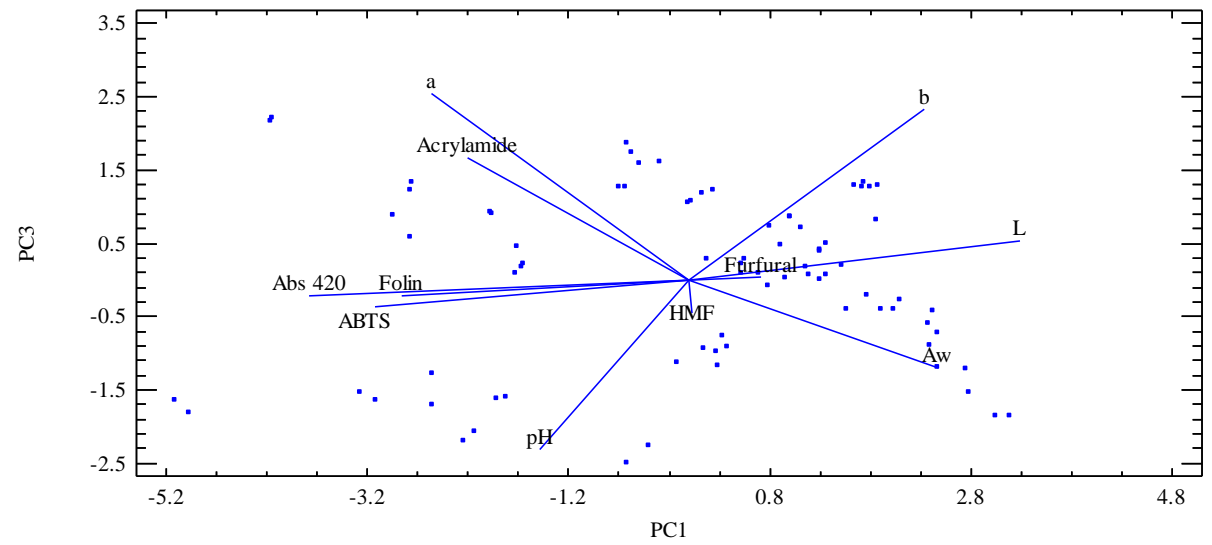

b

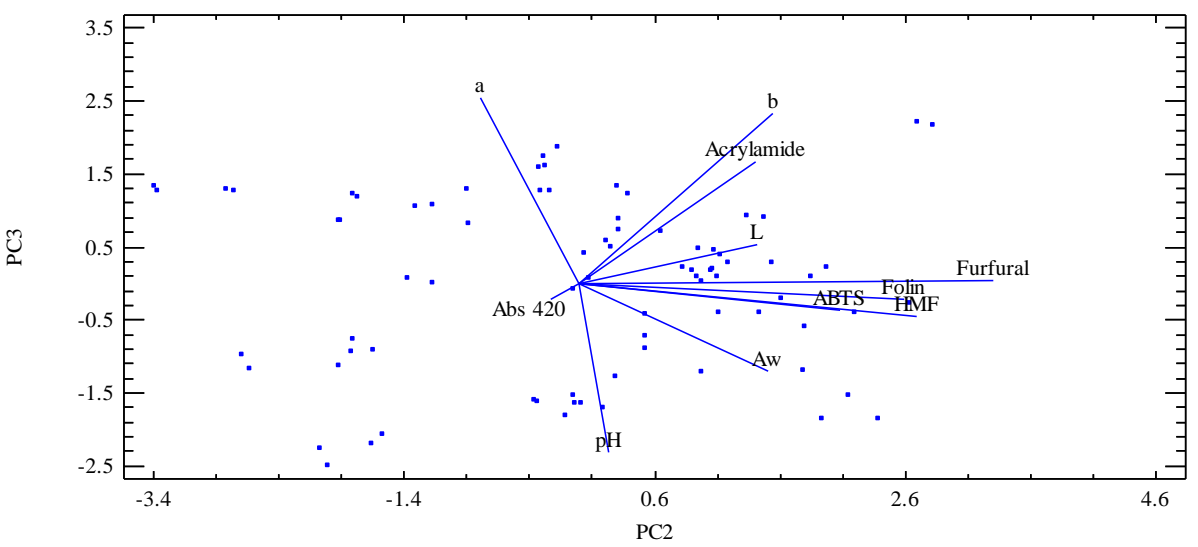

C 
Figure 2. Clusters formed from panela samples according to PCI and PC2. B: block and G: granulated.

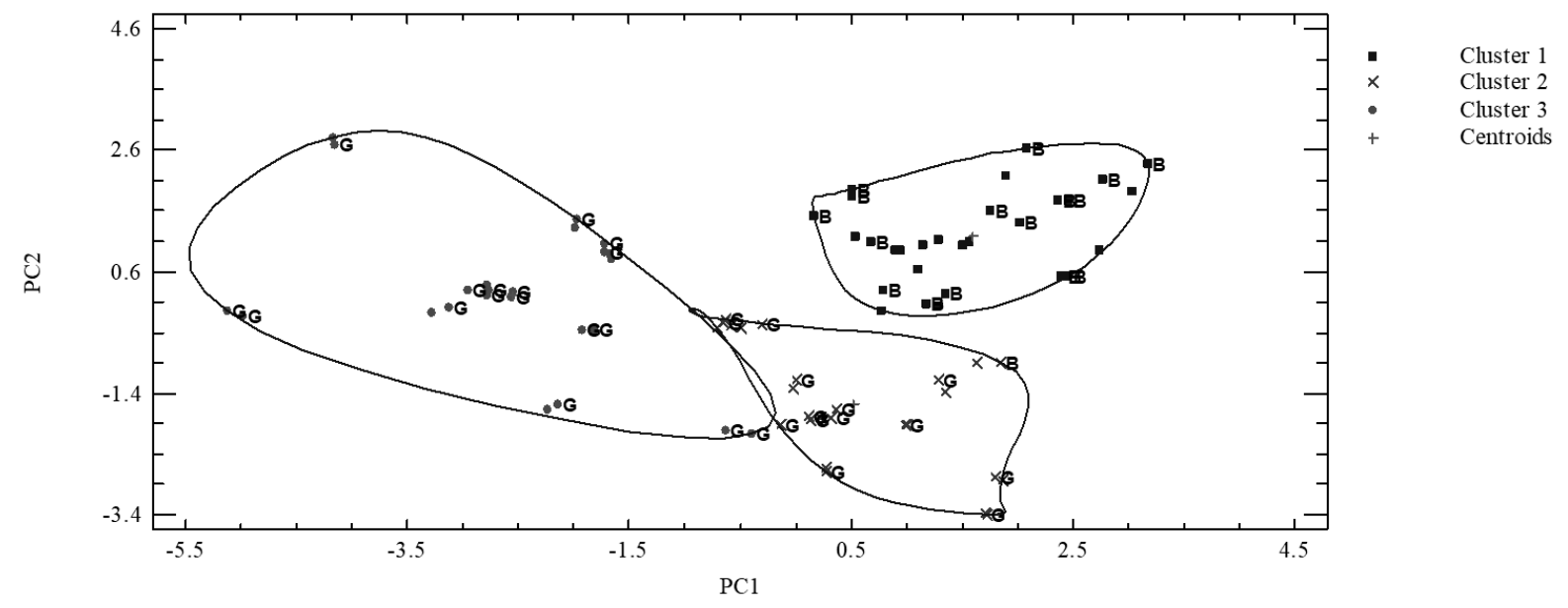

